\title{
Tempos de pandemia: E agora José? As aulas são online
}

\author{
Pandemic Times: What now José? The classes are online
}

\section{Ivonete Nink Soares}

Universidade Federal do Acre - UFAC - Acre - Brasil

\begin{abstract}
Resumo: Neste estudo será abordado o momento de pandemia no Brasil, relacionando-o com o contexto educacional, para discutir sobre o processo de capacitação dos professores e alunos para atuarem nas aulas remotas. O objetivo é apresentar, dentro de uma perspectiva empírica, com aportes teóricos, as inquietações dos sujeitos envolvidos nesse processo de ensino e aprendizagem, frente à urgência de estar letrado com as Tecnologias Digitais de Informação e Comunicação (TDICs), ter o letramento digital. Discorre-se sobre a dificuldade dos professores, alunos, juntamente com os responsáveis, em saber utilizar as ferramentas digitais para as aulas remotas, visto que não era suficiente ter um celular e/ou um computador de última geração, era preciso utilizá-lo para fins pedagógicos. A discussão apresentada foi vivenciada em Rondônia. Nesse contexto, foi possível observar como o manuseio das tecnologias foi favorecido em tempos de pandemia. Houve provocação e intensificação do uso das TDCls. Isso, certamente, deixou um legado para o aluno que pôde utilizar a tecnologia em prol do aprendizado escolar. Conclui-se, após essa vivência, que os envolvidos no processo das aulas remotas estão melhores preparados para atuarem nas práticas sociais que envolvem as ferramentas digitais.
\end{abstract}

Palavras-chave: Pandemia, TDICs, Letramento Digital.

Abstract: In this study, will be approached the pandemic moment in Brazil, relating it to the educational context, to discuss the process of training teachers and students to work in remote classes. The objective is to present, within an empirical perspective, with theoretical contributions, the concerns of the subjects involved in this teaching and learning process, in view of the urgency of being literate with Digital Information and Communication Technologies (TDICs), having digital literacy. It is discussed the difficulty of teachers, students, together with those responsible, in knowing how to use digital tools for remote classes, since it was not enough to have a cell phone and/or a last generation computer, it was necessary to use it to pedagogical purposes. The discussion presented was experienced in Rondônia. In this context, it was possible to observe how the handling of technologies was favored in times of pandemic. There was provocation and intensification of the use of TDCls. This certainly left a legacy for the student who was able to use technology for school learning. It is concluded, after this experience, that those involved in the process of remote classes are better prepared to act in the social practices that involve digital tools.

Keywords: Pandemic. TDICs. Digital Literacy. 


\section{Introdução}

Pensar em uma sociedade, em pleno século XXI, sem apropriar-se de alguma comunicação mediada por computador, novas tecnologias ou ferramentas digitais é algo inimaginável, diria até, fora da realidade. Assim como afirmam Barton e Lee (2015, p. 12) "os usuários de tecnologia se reapropriam de tecnologias para facilitar suas atividades cotidianas. Isto tudo tem acontecido no período relativamente curto e se tornou rotineiro e despercebido na vida das pessoas".

Estamos na era digital, os recursos tecnológicos digitais estão presente na vida das pessoas, de modo geral, e envolve quase tudo que as cerca, de forma explícita e/ou implícita. Eles não são novos, assim como reafirmam Barton e Lee (2015, p. 20) "As novas tecnologias não são mais novas: e-mail e mensagens instantâneas são referidos como mídias velhas, [...]. A ideia de se comunicar online participar de atividades virtuais era nova na década de 1990".

Os recursos, as ferramentas, os aplicativos e as possibilidades de utilização desses itens digitais são impossíveis de serem listados. Cada pessoa faz uso dessas tecnologias de diferentes formas para alcançar seus próprios propósitos, suprir suas necessidades, suas demandas, em diferentes contextos.

No mercado de trabalho são raros os setores, no momento não me recordo de nenhum, que consegue seguir 0 expediente sem nenhuma influência de recursos tecnológicos, seja no ato de registrar a presença do funcionário, no controle de estoque, na emissão de notas fiscais, nas trocas de e-mails, nas propagandas dos produtos e/ou serviços, enfim, em alguma atividade.

Nas escolas públicas, de Rondônia, de modo geral, essa também é uma constatação possível. Esses ambientes são entrelaçados por recursos tecnológicos digitais, sejam os computadores, a internet, os diários eletrônicos, os e-mails, os grupos de WhatsApp etc., em maior ou menor quantidade, há utilização de ferramentas digitais. Entretanto, quando o assunto é o processo de ensino e aprendizagem, a situação é diferente.

A pandemia surgiu e trouxe com ela a necessidade latente de rever práticas pedagógicas, ferramentas de ensino e colocar-se na postura de aprendiz, tanto docentes, quanto discentes e os responsáveis que acompanham o processo escolar. Nas palavras de Ribeiro (2018, p. 78), “Aprender é extensivo a professores, pais e dirigentes, assim como ensinar". Por isso, a inquietação frente à urgência de estar letrado com as Tecnologias Digitais de Informação e Comunicação (TDICs), ter o letramento digital.

\section{E agora, José? As aulas são online}

Até o mês de fevereiro do ano de 2020, em meu contexto, um número reduzido de professores planejava suas aulas utilizando os recursos tecnológicos, as ferramentas digitais. Dessas, destacavam-se as projeções de vídeos e os slides. Não havia uma utilização de recursos digitais, em favor do processo de ensino e aprendizagem, em massa, o movimento era discreto, cada docente o fazia à medida que sentia necessidade ou interesse. Nas palavras de Ribeiro (2018, p. 107), “O 'interesse' nos moverá na direção de qualquer dispositivo. Ou a necessidade, em segunda instância, quando já não há mais como desviar ou evitar". E o inevitável aconteceu.

O Brasil, assim como outros países, o mundo inteiro, deparou-se com a pandemia, a disseminação de um novo vírus, coronavírus, causando a COVID19. Essa nova doença, ainda sem controle, sem vacina, sem remédios, sem diagnósticos e causas esclarecidas, fez com que a população fizesse o que, no momento, poderia ser feito, o isolamento social, ou seja, todas as pessoas que não fossem dos serviços essenciais deveriam ficar em casa.

$\mathrm{O}$ isolamento social afetou todos os setores brasileiros, em especial a educação, o ambiente escolar, por ser um local de grande aglomeração de pessoas. A escola, de modo geral, os pais, os alunos, os professores estavam diante de um novo cenário. 
As dúvidas surgiam, o "novo normal" implicava, principalmente ao docente, motivos para questionarse.

Peço licença ao leitor e ao saudoso Carlos Drummond de Andrade (1942), enquanto professora, para parodiar nossas/minhas inquietações: "E agora, José? As aulas são online. Os alunos saíram, a escola fechou. A pandemia chegou, e agora, José? E agora, você? Você que é professor, que ensina os outros, você que faz a diferença, que leciona, protesta? E agora, José?"

As reflexões e questionamentos eram intensos, a situação emergente exigia que fossem pensados novos caminhos para a educação e, certamente, aos docentes incumbia a necessidade de reformulação de suas práticas pedagógicas e suas intenções de ensino. As mudanças e tomadas de decisões, guiadas pela necessidade, mobilizaria bem mais seus conhecimentos na tentativa de acabar com o hiato entre teoria e prática.

É de alta relevância encontrar uma ferramenta e testá-la; montar um plano de aula e pilotá-lo; verificar a receptividade de um dispositivo, lidar com os seus problemas, observar erros e acertos, ajustar, replicar, estabilizar uma aula, até que surjam novas possibilidades para ela. (RIBEIRO, 2018, p. 110)

A responsabilidade era imensa, 0

conhecimento de que as ferramentas digitais, quando bem aplicadas, favorecem a aprendizagem já não eram incógnitas, a questão era saber como e quando aplicá-las de forma satisfatória, dentro das possibilidades dos estudantes.

\section{E agora, José? E tudo começou, e tudo} exigiu

Nesse contexto de pandemia, a escola, enquanto instituição oficial de ensino, viu-se diante da necessidade de retomar as aulas, porém na modalidade de aulas remotas. Não havia tempo hábil para formação e capacitação dos professores, no que se refere à utilização das tecnologias digitais de informação e comunicação (TDICs), o uso era emergente.
Mais uma vez, apoio-me em Drummond e inquieto-me: "Está sem escola, está sem sala de aula, está sem formação, já não pode adiar, já não pode esperar, procrastinar já não pode, o novo normal chegou, o curso não veio, a capacitação não veio, o socorro não veio, não veio a utopia e tudo começou e tudo exigiu e tudo cobrou, e agora, José?"

O professor, que não estava capacitado, iniciou uma "corrida contra o tempo", tornou-se autodidata. Aprendeu para ensinar. Precisou mudar suas metodologias, repensar sua prática docente, testar, experienciar, julgar, adaptar e oferecer suporte aos alunos que não tinham habilidade para fazer uso das novas ferramentas de aprendizagem.

O educador que não sabia ou não tinha sido oportunizado a familiarizar-se com as TDCls precisou aprender e selecionar recursos que pudessem trazer melhores resultados para a aprendizagem. Para muitos, isso foi momento de muita angústia, porque, infelizmente, faltavam capacitações e instrumentos (computador, celular, internet etc.) que pudessem facilitar o processo.

Preparar aulas tornou-se um grande desafio, as tentativas, erros e acertos não podiam mais ser listados. Em consenso com essa constatação, Ribeiro (2018, p. 109-110) menciona:

Considerando-se o professor, seja a idade que tenha ou seu tempo de experiência profissional como usuário de TICs, o passo seguinte é ele conseguir relacionar os objetivos de sua aula ou certo conteúdo a algum novo modo de ensinar empregando tecnologias digitais.

Isso, por si só, já era um grande desafio, não bastava empregar uma tecnologia digital que favorecesse a aprendizagem dos conteúdos, precisava associar ao aluno, à disponibilidade de recursos disponíveis pela maioria e dar suporte, ser andaime, aos que não tinham habilidade para manusear as ferramentas.

Freitas (2012, p. 68) aborda essa questão ao afirmar que: "O par mais competente fornece $\mathrm{O}$ suporte, e o novato faz sua parte, amparado pelo mediador. Com o crescimento do aprendiz, o apoio do outro vai sendo gradualmente retirado e o iniciante, 
por etapas, passa a realizar o trabalho sozinho". Isso foi realizado.

Por determinação da escola, cada professor buscou contato com alunos, a maioria, pelas redes sociais, solicitando contato via WhatsApp para passar maiores instruções sobre as aulas que aconteceriam pela plataforma Google Sala de Aula (Classroom) .

Em algumas horas, o professor havia organizado grupos de WhatsApp, separado os alunos por turmas e dado as primeiras instruções de acesso ao Classroom. Ou seja, a escola, no papel do professor, estava ensinando os alunos a manipular as ferramentas digitais. Algo que serviria além dos muros escolares, uma aprendizagem significativa, um letramento.

De acordo com Botelho (2012, p. 26) "A preocupação das escolas, como a principal geradora de sujeitos letrados, tem sido com a alfabetização, que é apenas uns dos tipos de práticas do letramento". Agora o momento exigia o letramento digital. Mas afinal, o que vêm a ser o letramento e o letramento digital?

Esse termo surgiu no ano de 1995, no Brasil, nos estudos de Angela Kleiman e Leda Verdiani Tfouni, respectivamente, nos livros, "Os significados do letramento" e "Alfabetização e Letramento". Atualmente, diversos autores se apropriaram da nomenclatura e fazem suas definições. Botelho (2012, p. 24) elucida que "letramento é a habilidade de emprego de todas as possíveis demandas de leitura e escrita por parte dos usuários de um grupo social" e Ribeiro (2018, p. 40) corrobora: "é uma prática social, isto é, mais do que uma tarefa escolar ou uma demanda localizada, trata-se de um fazer ou de um participar da vida em sociedade, por meio da cultura escrita". Ou seja, o ensino que a escola estava oportunizando o aluno lhe serviria para diversas outras atividades.

Em suma, o letramento vai muito além do saber decodificar palavras, é dominar a leitura e a escrita nas práticas sociais. E nas práticas sociais atuais há grande exigência quanto ao saber usar as ferramentas digitais, daí a necessidade de o aluno participar do processo de letramentos digitais, definido por Dudeney, Hockly e Pegrum (2016, p. 17) como: "habilidades individuais e sociais necessárias para interpretar, administrar, compartilhar e criar sentido eficazmente no âmbito crescente dos canais de comunicação digital". Ou seja, a escola estava ensinando, de fato, para a vida, para a inserção do cidadão na era digital.

Estamos preparando estudantes para
um futuro cujos contornos são, na
melhor das perspectivas, nebulosos.
Não sabemos que novos postos de
trabalho existirão. Não sabemos quais
novos problemas sociais e políticos
emergirão. Mesmo assim estamos
começando a desenvolver um retrato
mais claro das competências
necessárias para eles poderem
participar de economias e sociedades
pós-industriais digitalmente
interconectadas. (DUDENEY, HOCKLY
e PEGRUM, 2016, p. 17).

Se um aluno tem um celular/computador não significa que ele já sabe participar das aulas remotas, já conhece todas as ferramentas, a maioria precisa ser ensinada. Não basta saber que o celular tira fotos, precisa saber que essas fotos, prints, imagens, podem ser transformadas em arquivos, documentos, anexadas, editadas, encaminhadas, inseridas no Word, no PDF etc. Esses ensinamentos são úteis para diversas outras atividades que envolvem os recursos digitais, as ferramentas.

\section{E agora, José? Sua loucura e sanidade}

Independente de componente curricular, o que estava sendo ensinado no momento eram habilidades digitais. Para isso foi necessário a utilização de áudios, prints, vídeos instrucionais, links de tutoriais etc., uma gama de meios alternativos para cumprir o propósito de oferecer conhecimentos tecnológicos necessários, a priori, para as aulas remotas.

Ensinar um aluno, de forma presencial e individual, não é um grande obstáculo para o professor, a dificuldade é externada quando a distância existe, a demanda de atendimento individual é extremamente conturbada, por exemplo, 150 alunos solicitando serem ajudados ao mesmo tempo, via WhatsApp, geralmente, refazendo a pergunta sem ter ficado atento às instruções anteriormente 
mencionadas. Isso é um transtorno inenarrável para quem não viveu a ocasião.

Ao se deparar com esse cenário, a meu ver, resta respirar fundo, tentar manter a calma e usufruir, mais uma vez, da paródia do poema de Drummond: "E agora, José? Sua nova sala de aula, seu instante de temor, sua loucura e sanidade, sua biblioteca, seu planejamento de aulas, seu ambiente de trabalho, sua incoerência, seu ódio - e agora?".

Nem sempre as respostas são fáceis de serem percebidas, mas a persistência, seguramente, é característica do mediador apaixonado pela arte de ensinar.

A escola cumpria sua função, atendia a todos, à medida do possível. Nesse processo, não apenas os alunos recebiam capacitação, mas também alguns familiares que seriam o elo entre a escola e o aluno. O professor identificava estratégias que ajudavam a entender o funcionamento das ferramentas digitais, elucidava as dúvidas de alguns, elegia outro com maior destreza para fazer a mediação, servir de andaime para os demais, tudo isso em um espaço muito curto de tempo. Havia urgência para alojar os alunos em suas salas virtuais, criar gmails, criar senhas, baixar aplicativos etc.

Nesse viés, a escola cumpria o que Rojo (2013, p. 7) assevera: "É preciso que a instituição escolar prepare a população para um funcionamento da sociedade cada vez mais digital e também para buscar no ciberespaço um lugar para se encontrar, de maneira crítica, com diferenças e identidades múltiplas". Esse lugar para se encontrar é algo ainda prematuro para os que acabam de iniciar suas "vidas digitais", porém é algo que só poderá surgir a partir do primeiro contato com o mundo digital.

Nessa concepção, os alunos que, infelizmente, não puderam ser assistidos com as aulas remotas e tiveram que retirar atividades impressas na escola, não tiveram essa relação aproximada com as TDCls. Foram deixados à margem do processo digital, não por falta de esforço escolar, do docente, da família, mas por questões outras que não são objetos de apreciação neste estudo.

\section{E agora, José? Não existe lousa}

As ferramentas tradicionais de ensino, (quadro, giz, pincel etc.) tiveram que ser substituídas. As aulas remotas, exceto para os professores que dispunham desse material em casa e optaram por gravar videoaulas, dispensaram esses itens escolares. $O$ docente encontrou-se em um dilema para adotar ferramentas digitais que pudessem trazer aulas significativas para o alunado e, consequentemente, viu-se em reflexão. Ao parodiar Drummond, elucido: "Com o pincel na mão quer escrever na lousa, não existe lousa; quer voltar pra escola, mas a escola fechou; quer ir pra sua rotina, rotina não há mais. José, e agora?" As dúvidas eram inumeráveis.

\begin{abstract}
As novas tecnologias, aplicativos, ferramentas e dispositivos viabilizaram e intensificaram novas possibilidades de textos/discursos - hipertexto, multimídia e, depois, hipermídia - que, por seu turno, ampliaram a multissemiose ou multimodalidade dos próprios textos/discursos, passando a requisitar novos (multi)letramentos. (ROJO e MOURA, 2019, p. 26).
\end{abstract}

Partindo dessa premissa, constatou-se que além do aluno precisar fazer uso das tecnologias, do aplicativo Google Sala de Aula, dos computadores, dos celulares, dos tablets etc. seria exigido dele, também, o conhecimento, por exemplo, da compreensão da função de um hipertexto, definido por Rojo e Moura (2019, p. 196, grifo dos autores), usando uma pesquisa no site Wikipédia, como: "um texto ao qual se agregam outros conjuntos de informação na forma de blocos de textos, palavras, imagens ou sons, cujo acesso se dá através de referências específicas no meio digital denominadas hiperlinks, ou simplesmente links".

A cada modelo de atividade, com uso de ferramentas digitais diferentes, postada na sala virtual, surgia uma nova dúvida. $\mathrm{O}$ professor necessitava, além de agregar conhecimentos sobre seu componente curricular, dar suporte para os novos desafios digitais, proporcionar o letramento digital do estudante, conscientizar sobre a advertência mencionada por Dudeney, Hockly e Pegrum (2016, p. 
26), "os links exigem que os leitores decidam se aceitam convites para ir além do texto atual e se assumem a reponsabilidade pela escolha de seus próprios percursos narrativos na rede mais ampla".

Nas salas de aula, físicas, sempre houve a apropriação de multimídias, definidas por Rojo e Moura (2019, p. 40) como "combinação, na mesma tela, de textos escritos e imagens estáticas de maneira não remissiva".

Nos momentos que antecederam a pandemia no Brasil, a tela utilizada era a lousa, assim como esclarece Ribeiro (2018, p. 76): “já vínhamos, há séculos, desenhando, escrevendo em lousas. [...] $A$ aula multimídia não é novidade, absolutamente". Agora o que modificava era o suporte para a multimídia. Havia muito mais possibilidades.

Diante das probabilidades das multimídias, surgiu a hipermídia. De acordo com Santaella (2014, p. 214) "são imagens, sons, textos, animações e vídeos que podem ser conectados em combinações diversas, rompendo com a ideia linear de um texto com começo, meio e fim pré-determinados e fixos". Ou seja, uma gama de opções de textos digitais que exigem os multiletramentos.

Nessa nova acepção de letramento Rojo e Moura (2019, p. 24, grifo dos autores) esclarecem: "o termo 'letramento' embutido no conceito de multiletramentos abre cada vez mais espaço aos conceitos de mídia e de modalidade de linguagem, ganhando mais força, neste caso, o prefixo multi-". São muitos conhecimentos a serem apreendidos.

A mudança abrupta, no modelo das aulas, trazem, novamente, a inquietação na paródia de Drummond: "Se você gritasse, se você reclamasse, se você ignorasse a plataforma digital, se você dormisse, se você acordasse, se você desistisse... Mas você não desiste, você é professor, José!"

\section{E agora, José? Você persiste, José! José,} até quando?

As aulas expositivas sempre foram a base para as aulas presenciais. Em consonância, Ribeiro (2018, p. 76) assegura que: "[...] seria no mínimo incoerente tratar a tradicional aula expositiva como um problema, na atualidade. Falar e conversar sempre foram e sempre serão um modo eficaz e importante de ensinar e aprender". Por isso o professor, valendo-se das ferramentas digitais, fez uso das videoconferências.

Essas aulas puderam aproximar, ainda que de maneira digital, os integrantes do processo de ensino e aprendizagem. Entretanto, destacou a desigualdade social, visto que, em Rondônia, alguns alunos da escola pública, não tem o próprio celular, não tem internet de qualidade, utiliza 0 aparelho do responsável, do irmão, dos avós etc., a internet vem do vizinho, do amigo, do tio... Além do mais, as aulas, sendo em horário comercial, impossibilitou a participação da maioria dos alunos. E, sozinho na videoconferência, o docente, mais uma vez, parodia o texto de Drummond: "Sozinho na sala virtual, qual criança abandonada, sem interação, sem alunos para perguntar, poucas dúvidas a responder que te faça professor, você persiste, José! José, até quando?"

Até quando, não se sabe. O ano é atípico. As tentativas, erros e acertos são incontáveis. Deste ano, 2020, fica a certeza de que as aprendizagens referentes aos usos das ferramentas digitais permanecerão. Se houve algo de positivo, em tempos de pandemia, foi o favorecimento do uso intensificado das TDCls. Acredita-se que, não sendo neste contexto, as escolas, os alunos, os professores, os responsáveis, possivelmente, não teriam se empenhado tanto nesse modelo de aula.

As aulas, desse período de pandemia, extrapolaram as ementas curriculares, percebeu-se que os conteúdos ali elencados não convinham para a atualidade, não eram tão emergentes. Dessa forma, buscou-se, primeiramente, fazer o letramento digital, ainda com objetivos a serem alcançados, mas com êxitos e proficiência para alguns e, a partir daí, retomar, na medida do possível, para a ementa do componente curricular em consonância com a plataforma digital.

\section{Conclusão}


Sabe-se que não há uma política pública eficiente, capaz de preencher as lacunas da desigualdade, referente aos usos das tecnologias, porém esse não era o objetivo desse estudo. $O$ objetivo era demonstrar, dentro de uma perspectiva empírica, as inquietações de professores, alunos, juntamente com seus responsáveis, envolvidos no processo de ensino e aprendizagem, de Rondônia, frente à urgência de estar letrado com as Tecnologias Digitais de Informação e Comunicação (TDICs)

Ao término, conclui-se que se a escola não apresentasse ao aluno, não proporcionasse a utilização de recursos tecnológicos, de ferramentas digitais, uma porcentagem significativa da população brasileira demoraria muito mais tempo para saber digitar um texto no Word, editá-lo no Google Docs, anexar um documento, uma imagem, participar de um chat, criar e editar um vídeo, participar de uma videoconferência, dentre tantas outras possibilidades que os "novos" recursos tecnológicos nos proporcionam.

O legado que essa circunstância de ensino com aulas remotas deixa é a certeza de que é possível utilizar a tecnologia em favor da aprendizagem escolar. Entretanto, há muito ainda a ser melhorado. Não é possível admitir que a educação, que precisa ser inclusiva, se torne tão excludente devido ao acesso aos recursos tecnológicos e ferramentas digitais. $\mathrm{O}$ desenvolvimento das competências digitais, o letramento digital, dos alunos que não tiveram acesso à plataforma precisa acontecer. Esse letramento é algo necessário.

A parcela de contribuição escolar em relação ao uso das TDCls, até o momento, foi significativa, porém tem-se plena convicção de que ainda há uma grande lacuna a ser preenchida. Os sujeitos, que puderam participar das aulas remotas, seguramente, estão melhores preparados para atuarem nas práticas sociais que envolvem as ferramentas digitais, não que eles já não participassem, mas a escola, cumprindo sua função de ensinar para além dos muros escolares, oportunizou novos conhecimentos e práticas.

\section{REFERÊNCIA}

BARTON, David. LEE, Carmen. Linguagem online: textos e práticas digitais. Tradução Milton Camargo Mota. - 1. ed. - São Paulo: Parábola Editorial, 2015.

BOTELHO, José Mário. Oralidade e escrita: sob a perspectiva do letramento. Jundiaí, Paco Editorial: 2012.

DUDENEY, Gavin; HOCKLY, Nicky; PEGRUM, Mark. Letramentos Digitais. Trad. Marcos Marcionilo. 1. ed. São Paulo: Parábola Editorial, 2016.

FREITAS, Vera Aparecida de Lucas. Mediação: estratégia facilitadora da compreensão leitora. In BORTONI-RICARDO, Stela Maris. (orgs.)... [et al.]. Leitura e Mediação Pedagógica - São Paulo: Parábola Editorial, 2012. cap. 3, p. 65-85.

RIBEIRO, Ana Elisa. Escrever hoje: palavra, imagem e tecnologias digitais na educação. 1. ed. São Paulo: Parábola, 2018.

ROJO, Roxane (Org.). Escol@ conectada: os multiletramentos e as TICs. São Paulo: Parábola, 2013.

ROJO, Roxane. MOURA, Eduardo. Letramentos, mídias, linguagens. São Paulo: Parábola Editorial, 2019.

SANTAELLA, Lucia. Gêneros discursivos híbridos na era da hipermídia. Bakhtiniana, São Paulo, v. 9, n. 2, p. 206-216, 2014. Disponível em: https://revistas.pucsp.br/bakhtiniana/article/view/1951 6. Acesso em: 24 ago. 2020

NINK, Ivonete Soares. Tempos de pandemia: E agora, José? As aulas são online. Signo, Santa Cruz do Sul, v. 46, n. 85, p. 284-291, jan. 2021. ISSN 1982-2014. Disponível em: $<$ https://online.unisc.br/seer/index.php/signo/article/view/15646 >. doi:https://doi.org/10.17058/signo.v46i85.15646. 